Tropical Journal of Pharmaceutical Research October 2012; 11 (5): 753-758

(C) Pharmacotherapy Group,

Faculty of Pharmacy, University of Benin

Benin City, 300001 Nigeria.

All rights reserved.

Available online at http://www.tjpr.org http://dx.doi.org/10.4314/tjpr.v11i5.8

Research Article

\title{
Hair Growth Promotant Activity of Petroleum Ether Root Extract of Glycyrrhiza Glabra L (Fabaceae) in Female Rats
}

\author{
Sukirti Upadhyay ${ }^{1^{*}}$, Ashoke K Ghosh ${ }^{1}$ and Vijender Singh ${ }^{2}$ \\ ${ }^{1}$ College of Pharmacy, IFTM, Moradabad-244001 (U P), ${ }^{2}$ Aimil Pharmaceuticals (India) Ltd, New Delhi-110008, India.
}

\begin{abstract}
Purpose: To investigate the effect of Glycyrrhiza glabra root extract on hair growth in female Wistar rats.

Methods: Female Wistar rats were used for the hair growth promotion studies. They were divided into three groups $(n=6)$ and their dorsal skin was completely denuded to completely remove hair. Paraffin oil (control), $2 \%$ minoxidil solution (reference) or petroleum ether $\left(60-80^{\circ} \mathrm{C}\right)$ root extract of $\mathrm{G}$. glabra (2 $\%)$, was applied to the denuded skin once daily for 30 days. During this period, they were observed visually for hair growth and thereafter skin biopsy was taken for evaluation of follicular density and cyclic phases of hair growth.

Results: Animals treated with petroleum ether extract of G. glabra roots showed longer hair than those treated with either minoxidil or control. Furthermore, the time (5-13 days) for commencement of hair growth and to reach complete hair growth was least in extract-treated animals, followed by those treated with minoxidil (6 - 19 days). A maximum of $76 \%$ of hair follicles were in anagenic stage (active growth phase of hair) in extract-treated animals, compared to 66 and $45 \%$ in minoxidil-treated and control groups, respectively.

Conclusion: This study indicates that the petroleum ether extract of G. glabra roots has potentials as a hair growth promoting agent for females.
\end{abstract}

Keywords: Hair growth promotant, G. glabra, Minoxidil

*Corresponding author: Email: sukirtiupadhyay@gmail.com; Tel: +91-9410478954 


\section{INTRODUCTION}

Hair loss is a dermatologic disorder, and the search for natural products with hair growth promoting potential is continuing [1,2]. Hair loss, or alopecia, is a common patient complaint and a source of significant psychologic and physical stress [3]. Androgens are considered to be one of the most important causes for alopecia apart from a variety of other factors [4]. Natural products in the form of herbal formulations are available in the market and are used as hair tonic, hair growth promotant, hair conditioner, hair-cleansing agent, antidandruff agent, as well as for the treatment of alopecia and lice infection [5].

G. glabra, also known as Yasthi-madhu in Sanskrit, Jethi-madhu in Hindi, Jashtimadhu in Bengali (all Indian languages), and licorice in English, is cultivated in Jammu, Kashmir, Punjab and Sub-Himalayan tracts of India. It is a hardy herb or undershurb, attaining a height of $1.8 \mathrm{~m}$. Its roots are thick, having many branches with red or lemon colour outside and yellowish or pale inside. It is called Keshya (hair growth promoter) in traditional texts of Ayurveda [6].

The decoction of the root is a good wash for falling and graying hair [7]. Hence, the present study is focused on the experimental investigation of the hair growth potential of Glycyrrhiza glabra Linn (Fabaceae) in female rats.

\section{EXPERIMENTAL}

\section{Plant material}

G. glabra roots were procured in the month of June 2011 from Corbett National Park, Ramnagar (Uttarakhand, India) and identified by Dr DV Amla, of National Botanical Research Institute (NBRI), Lucknow, Uttar Pradesh, India, and a voucher specimen (no. NBRI-SOP- 202) was preserved in NBRI for future reference.

\section{Preparation of extract}

The plant material was dried under the shade, then in an oven at $30{ }^{\circ} \mathrm{C}$, and thereafter reduced to powder form. The powdered material $(100 \mathrm{~g})$ was extracted in a Soxhlet apparatus with petroleum ether (60 $80^{\circ} \mathrm{C}$ ) for $18 \mathrm{~h}$. The extract was filtered and dried under reduced pressure to give a dry yield of $1.6 \%$.w/w.

\section{Phytochemical analysis}

The extract was screened for its phytochemical contentss while chromatography was performed to develop a suitable solvent system. The detecting agent used in this regard was Lieberman Burchard reagent in a UV chamber at a wavelength of $360 \mathrm{~nm}$

\section{Animals}

Healthy female Wistar albino rats, weighing $120-150 \mathrm{~g}$ and aged 3 - 4 months were used for hair growth promotion studies. The animals were handled according to CPCSEA Guidelines of Good Laboratory Practice [8]. The research protocol of the animal experimentation (Reg no. 837/ac/04/ CPCSEA; Resolution no. 05/837ac/PH/10 of December 12, 2010) was approved by the 'Institutional Animal Ethical Committee' of College of Pharmacy, IFTM, Moradabad244001, Uttar Pradesh, India. The rats were placed in cages and kept in standard environmental conditions of $12 \mathrm{~h}$ light and 12 h dark cycle, $23 \pm 2{ }^{\circ} \mathrm{C}$ and $35-60 \% \mathrm{RH}$. They were fed with standard diet ad libitum with free access to water.

\section{Chemicals}

Minoxidil was purchased from Dr Reddy Lab, Hyderabad, India while petroleum ether, ethanol and paraffin oil were obtained from Central Drug House, Delhi, India. 


\section{Preparation and design of treatment}

The extract $(2 \mathrm{~g})$ was dissolved in $100 \mathrm{~mL}$ paraffin oil while a commercial brand of minoxidil (Mintop $\AA$ ) was used as reference standard. The animals were divided into three groups of six animals each. The control group was treated with only paraffin oil. The reference group was treated with minoxidil while the test group was treated with the extract ( $2 \% w / v$ in paraffin oil).

\section{Toxicity studies}

Toxicity studies were carried out by applying the extract to the denuded rat skin in concentrations of up to $10 \%$ for 7 days. The extract was considered safe for animal tests when it did not show any toxic effects or erythema on the rat skin [9].

\section{Hair growth studies}

A $4 \mathrm{~cm}^{2}$ area of the dorsal skin of the rats was shaved off using Anne French cream (a marketed hair removal cream) and cleansed with surgical spirit [10]. The extract solution or vehicle or minoxidil $(0.4 \mathrm{ml})$ was applied to the denuded area of the rat once a day. This treatment was continued for 30 days during which hair growth pattern was observed visually and recorded. Skin biopsy was done on the skin on the 30th day of treatment and tissue used for follicular analysis by histopathology. Hair growth initiation and completion times was evaluated by observing the animal skin from the time the hairs sprouted to and the time fullength was attained. Hair length was measured 25 hairs plucked randomly from the test area of each animal. Anagen to telogen ratio was determined by observing the follicular morphology in the microscope with the aid of an ocular micrometer in the eye piece of microscope. .

\section{Statistical analysis}

Statistical analysis of the data was carried out by one-way ANOVA in respect of the test and control groups, followed by Dunnett's test. Differences between data were considered highly significant $p<0.001$. The software used was Instat, version 2.1. The data are reported as mean \pm SEM.

\section{RESULTS}

\section{Phytochemical analysis}

The petroleum ether extract of G.glabra showed presence of steroids. Its chromatograohic profile gave four separations in toluene: ethyl acetate (90:10) solvent system.

\section{Hair growth}

All the three groups of animals were observed for hair growth initiation and completion time. Extract treated animals showed significant reduction in hair growth initiation and completion time as compared to control and minoxidil treated animals. (Table 1)

Table 1: Time taken for initiation and completion of hair growth

\begin{tabular}{lcc}
\hline Treatment & $\begin{array}{c}\text { Initiation } \\
\text { time (day) }\end{array}$ & $\begin{array}{c}\text { Completion } \\
\text { time (day) }\end{array}$ \\
\hline Control & 10 & 23 \\
Minoxidil & $6^{* * *}$ & $19^{* * *}$ \\
Extract & $5^{\star * *}$ & $13^{\star * *}$ \\
\hline${ }^{* \star *} p<0.001$, significance Vs control &
\end{tabular}

Hair growth initiation and completion times were significantly lower $50 \%$ to $56 \%$ in extracttreated animals than in control animals. The extract treated animals showed $26.2 \%$ and $36.6 \%$ longer hair than minoxidil-treated and control groups, respectively.

\section{Quantitative studies}

The photomicrographs obtained indicate that minoxidil-treated animals (Fig 2a) had fewer anagenic hair follicles while the extractedtreated animals showed maximum number of anagenic hair follicles and higher follicle density (Fig 2b). 

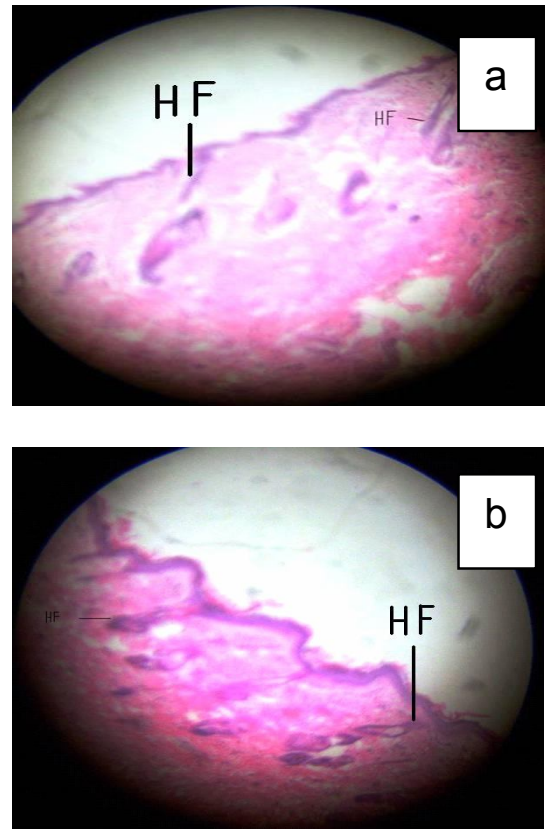

Fig 2: Photmicrograph of (a) minoxidil-treated rat skin and (b) extract-treated rat skin.

Note: The extract-treated skin shows higher follicle density and more anagenic follicles

The skin of the extract-treated group exhibited more anagenic than telogenic hair. It also, had 69.6 and 13,0 \% more anagenic hair follicles than the control and minoxidiltreated group, respectively.

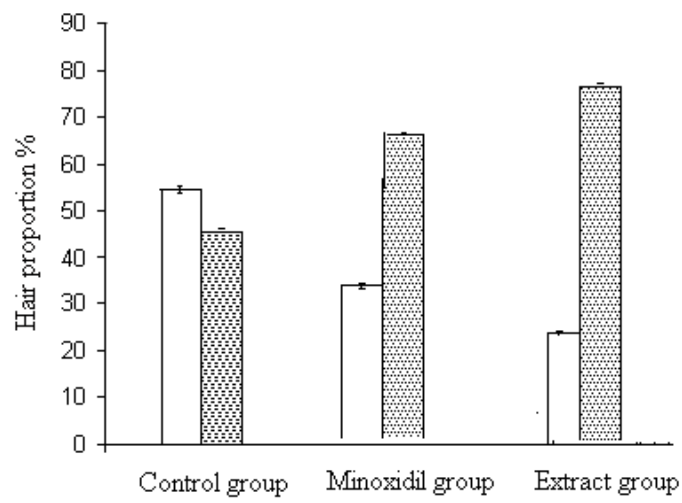

Fig 3: Hair growth proportion (anagen versus telogen) of rat skin following treatment/ Note: Shaded bars = anagen; plain bars = telogen .

\section{DISCUSSION}

There exists an unmet need for effective novel hair growth enhancers as there are only two drugs, topical minoxidil and oral finasteride, approved by the United States Food and Drug Administration (FDA) for the treatment of alopecia. Large randomized placebo controlled trials on humans conducted by Upjohn Company for minoxidil, a potassium channel opener, showed efficacy in $54 \%$ of the treated patients compared to $34 \%$ in placebo (control) group [11]. There are significant adverse dermatological effects associated with minoxidil such as pruritis, dryness, scaling, local irritation and dermatitis [11]. Among those who received finasteride treatment in one year, $48 \%$ of hair re-growth was observed. Patients receiving finasteride observed that it is generally well tolerated, but a few withdrew from the treatment programme due to drug-related sexual disorders. Finasteride is not indicated for use in women [12].

The petroleum ether extract of G. glabra showed hair growth promotion activity as the extract treated animals developed longer, denser, anagenic hair and took less time for hair to cover the denuded skin of female rats, compared to control and minoxidil-treated groups. Thus, minoxidil (reference) was a more effective hair growth enhancer than the control group but was inferior to the $2 \%$ extract-treated group probably due the fact that G. glabra extract has some estrogenic property [13]. Estrogen prolongs the anagenic phase of hair growth, thus promoting hair growth. The extract probably affected androgen metabolism [14,15]. Androgens are responsible for hair loss. They lower serum testosterone levels in females $[14,15]$. It is probable therefore that the hair growth promoting effect of the extract is due to hormonal modulation. Apparently, the extract would not cause any harmful systemic effect following topical administration. Consequently, it is apparent that the petroleum ether extract of $G$. glabra 
possesses exhibits hair growth promotion activity.

A recent study on Eclipta alba herb which validate it as a hair growth promoter showed that the presence of antigen FGF-7 and Shh and absence of BMP4 favoured anagenic state of hair [16]. In this study, a higher proportion of anagenic hair follicles, vis-a-vis telogenic hair follicles, was found on extracttreated rat skin than on control and minoxidiltreated skins. As anagen is a stage in which the follicle grows while telogen is the stage when follicle is shed. However, further studies, including immunohistochemical investigations, of skin cells, are required to fully elucidate the mechanism of hair growth promotion by the petroleum ether root extract of G. glabra.

\section{CONCLUSION}

The petroleum ether root extract of G. glabra is more effective than minoxidil in promoting hair growth in female wistar rats. If fully developed, it has the potential of surpassing minoxidil which currently is widely used for hair growth promotion and is categorized as a lifestyle drug [17]. The herbal extract would be preferred, not only because of its natural origin but also because minoxidil possesses several side effects

\section{COMPETING INTEREST}

The authors declare no conflict of interest.

\section{ACKNOWLEDGEMENT}

The authors are thankful to Dr RM Dubey, Director, College of Pharmacy, I.F.T.M., for providing the research facilities for this work and Prof R Somvanshi of Indian Veterinary Research Institute, Izatnagar,India for help with histopathological studies This paper is based, in part, on the PhD dissertation of SM Upadhyay at GB Technical University, Lucknow, India

\section{REFERENCES}

1. Arakawa $T$, Emoto $K$, Utsnomiya $S$, Hagiwara $Y$, Shimizu T.Effect of Swertinogen in hair growth with special reference to its activities on skin function. Tokushima J Exp Med1962; 9: 3759.

2. Adhirajan N, Ravi Kumar T, Shanmugasundaram N, Babu M .In vivo and in vitro evaluation of hair growth potential of Hibiscus rosasinensis Linn. J Ethnopharmacol 2003; 88: 235-239.

3. Han A, Mirmirani P. Clinical approach to the patient with alopecia. Semin Cutan Med Surg 2006; 25: 11-23.

4. Bagatell C, Bremner WJ. Androgens in men - uses and abuses. New Engl J Med 1996;334: 707715.

5. Olsen EA. Androgenetic alopecia. Disorders of Hair Growth: Diagnosis and Treatment. New York McGraw Hill ; 1993I pp 257-287

6. Chatterjee $A$, Pakrashi S. The treatise of Indian medicinal plants. National Institute of Sci Commun, New Delhi 1992; pp 67-180.

7. Singh J, Tripath, A, Gandhi R, Singh S.C,Jain S.P, Sharma A, Khanuja SPS Traditional uses of Glycyrrhiza glabra (mulethi/yastimadhu).J Med Aromatic Plant Sci 2006; 28(2): 263-269.

8. Ministry of Environment and Forests, Government of India Public information: Good Practices: CPCSEA guidelines [Cited 2012 May 26]. Available from: $h$ ttp://moef.nic.in.

9. A.S.T.M. Standard Practice for testing biomaterials in rabbits for primary skin irritation, A.S.T.M. designation F719-81; Philadelphia: American Society for Testing of Materials 1998; pp 178179.

10.Adhirajan N, Dixit V K, Gowri C. Development and evaluation of herbal formulation for hair growth. Indian Drugs 2001; 38(11): 559-563.

11. Spindler JR. The safety of topical minoxidil solution in the treatment of pattern baldness: The results of a 27-center trial, Clin Dermatol, 1988; 6: 200-212.

12. McClellan, J. Karen, Markham, Anthony. Finesteride. $A$ review of its use in male pattern hair loss. Drugs 1999; 57(1): 111-126.

13. Somjen $D$, Knoll E, Jacob V , Naftali $S$, Tamir $S$ .Estrogen-like activity of licorice root constituents:glabridin and glabrene, in vascular tissues in vitro and in vivo. J Steroid Biochem Mol Biol 2004; 91: 147-155.

14. Yaginuma $T$, Izumi $R$, Yasui $H$, Arai $T$, Kawabata $M$. Effect of traditional herbal medicine on serum testosterone levels and its induction of regular ovulation in hyperandrogenic and oligomenorrheic women (Article in Japanese). Nippon Sanka Fujinka Gakkai Zasshi 1982; 34(7): 939-944.

15. Josephs RA, Guinn JS, Harper LM, Askari F. Liquorice consumption and salivary testosterone concentrations. Lancet 2001; 358: 1613-1614. 


\section{Upadhyay et al}

16. Dattaa $K$, Singha TA, Mukherjee $A$, Bhata $B$, Ramesh B, Burmana AC. Eclipta alba extract with potential for hair growth promoting activity. J Ethnopharmacol 2009; 124: 450456.
17. Kunte $Y$, Sucklecha A, Rahman SJ. Life style drug concept and impact on society. Indian J Pharm Sci 2010; 72(4): 409-413. 